\title{
IMPACTO DE CORTO Y MEDIANO PLAZO DEL COVID-19 EN LA ECONOMÍA DOMINICANA: UN ANÁLISIS DE OFERTA Y DEMANDA AGREGADA
}

\author{
Alexis Cruz-Rodríguez ${ }^{1}$ \\ Recibido: 26/5/2021 • Aceptado: 18/10/2021
}

Cómo citar: Cruz-Rodríguez, A. (2021). Impacto de corto y mediano plazo del COVID-19 en la economía dominicana: un análisis de oferta y demanda agregada. Ciencia, Economía y Negocios, 5(2), 39-60. Doi: https://doi.org/10.22206/ceyn.2021.v5i2.pp39-60

\begin{abstract}
Resumen
El objetivo del presente trabajo es ilustrar el impacto económico de la pandemia COVID-19 en la economía dominicana. Para ello, se desarrolla un modelo de OA y DA, para el mediano plazo, y un modelo IS-RM para el corto plazo, dentro del marco de la nueva economía keynesiana con la política monetaria siguiendo una regla de Taylor y la oferta agregada se modela a partir de la curva de Phillips. El análisis indica que, tanto en el corto como en el mediano plazo, el impacto del coronavirus se traduce en pérdidas en el nivel de producción, mayores niveles de desempleo y depreciación del tipo de cambio real. Las expectativas de los consumidores y de los empresarios juegan un papel importante.
\end{abstract}

Palabras clave: COVID-19, Crecimiento, inflación, demanda agregada, oferta agregada.

JEL clasificacion: E20, E23, F4, O4.

\footnotetext{
${ }^{1}$ Escuela de Economía, Instituto Tecnológico de Santo Domingo (INTEC), Santo Domingo, República Dominicana. Correo-e: alexis.cruz@intec.edu.do.

Agradezco los comentarios y sugerencias de Martín Francos y la valiosa asistencia de Judith Aquino. Todas las opiniones son de única responsabilidad del autor.
}

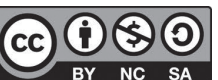




\title{
SHORT- AND MEDIUM-TERM IMPACT OF COVID-19 ON THE DOMINICAN ECONOMY: AN ANALYSIS OF AGGREGATE SUPPLY AND DEMAND
}

\author{
Alexis Cruz-Rodríguez \\ Received: $\mathrm{xxx} \bullet$ Approved: $\mathrm{xxx}$
}

\begin{abstract}
The objective of this article is to illustrate the economic impact of the COVID-19 pandemic on the Dominican economy. To do this, an OA and DA model is developed for the medium term, and an IS-RM model for the short term, within the framework of the new Keynesian economy with monetary policy following a Taylor rule and the money supply is a Phillips curve. The analysis indicates that both in the short and medium term the impact of the coronavirus translates into losses in the level of production, higher levels of unemployment and depreciation of the real exchange rate. The expectations of consumers and entrepreneurs play an important role.
\end{abstract}

Keywords: COVID-19, Growth, inflation, aggregate demand, aggregate supply.

JEL classification: E20, E23, F4, O4. 


\section{Introducción}

En diciembre de 2019 se detectó un brote epidémico en la ciudad de Wuhan, República Popular China, cuyo agente causante, en un principio desconocido, fue identificado como un nuevo coronavirus denominado SARS-CoV-2. Las medidas adoptadas por el país asiático, para contener la propagación, provocaron una ruptura en las cadenas mundiales de suministro, generando escasez en la oferta y una reducción de la mano de obra debido al confinamiento. No obstante, se produjo una rápida propagación del virus hacia el resto del mundo, conllevando a la Organización Mundial de la Salud (OMS) a declarar una pandemia el 11 de marzo de 2020.

Una vez que el COVID-19, como se le ha denominado, comenzó a propagarse a otras regiones provocó un impacto negativo significativo en la actividad económica de todos países del mundo. En consecuencia, los organismos internacionales (Banco Mundial, Fondo Monetario Internacional, OCDE y CEPAL, entre otros) redujeron sus proyecciones de crecimiento mundial para 2020 colocándolas a las puertas de una recesión global. De igual forma, la CEPAL proyectó que la economía de América Latina y el Caribe sufrirá una contracción de la actividad superior al 5.0\% en 2020, lo que generará casi 30 millones más de pobres.

En República Dominicana se reportó el primer caso el primero de marzo de 2020, tratándose de un turista italiano de 62 años que había llegado al país días antes y quien no presentaba síntomas al momento de su arribo. Tres días después, las autoridades de la salud pública reportaron seis nuevos casos, caracterizados por haber estado fuera del país en las dos semanas previas. Justo 16 días después de haber anunciado el primer caso importado, las autoridades de República Dominicana informaron la primera muerte de una paciente positiva al virus; la detección del primer caso de transmisión local y la confirmación de 21 casos positivos. Esa misma noche, la máxima autoridad del gobierno dominicano anunció una serie de medidas sanitarias, sociales y económicas, con el objetivo de combatir la propagación y contener el virus en el territorio nacional.

El presente documento busca entender, de una forma sencilla, el impacto, tanto en el corto como en el mediano plazo, del COVID-19 en la economía dominicana. Para ello, se utiliza un esquema simple de 
oferta y demanda agregada y un modelo IS-RM. El resto de este artículo está organizado de la siguiente manera: la sección 2 presenta las medidas adoptadas para contener la propagación y aliviar el impacto económico y social del virus. Una revisión de la literatura relacionada se presenta en la sección 3. En la sección 4 se presentan los aspectos metodológicos del modelo. En la sección 5 se analizan los impactos utilizando un instrumental gráfico. Finalmente, en la sección 6 se presentan algunas conclusiones y recomendaciones.

\section{2. ¿Cuáles medidas fueron tomadas para reducir la propagación y el impacto económico y social del virus?}

Una de las primeras medidas adoptadas por el gobierno dominicano fue la suspensión de los vuelos procedentes de Milán, hacia fines del mes de febrero de 2021, y a mediados de marzo fueron interrumpidos todos los vuelos procedentes de Europa, China, Corea e Irán. Asimismo, se anunció el cierre de las fronteras, por aire, mar y tierra, obligando al cierre de todas las instalaciones hoteleras, lo que impactó inmediatamente el turismo, considerado uno de los sectores más dinámico y generador de divisas del país, y que ya venía impactado desde mediados del año 2019 producto de una campańa negativa a nivel internacional. El gobierno también dispuso el cierre de las escuelas y universidades, y se suspendieron las actividades comerciales consideradas como no esenciales. Se solicitó a los diferentes sectores productivos implementar el teletrabajo siempre que fuera posible; y se prohibieron las reuniones y eventos nacionales e internacionales, de toda índole, así como actividades en bares y clubes, entre otros. Se prohibió la circulación de autobuses y minibuses urbanos e interurbanos, tanto públicos como privados, al igual que el metro y el teleférico. El gobierno declaró el estado nacional de emergencia e implementó un toque de queda entre las cinco de la tarde y las seis de la mañana, y que se extendió (con algunas modificaciones) hasta principios del año 2021. Pero al igual que en el resto del mundo, todas esas disposiciones propiciaron una merma en el dinamismo económico del país, con excepción de los sectores que suministran servicios básicos.

Con miras a aminorar el impacto económico, el gobierno anunció medidas de apoyo a los sectores productivos permitiendo dividir, en 
cuatro cuotas, el pago del impuesto sobre la renta anual y el otorgamiento de facilidades de pago de los compromisos anticipados de todo el sector productivo. También, se suprimió temporalmente la tarifa a los Acuerdos de Precio Anticipado al sector hotelero, y fue autorizada la no aplicación de recargos o intereses, durante los meses de abril y mayo, a aquellos empleadores que no realicen a tiempo los aportes correspondientes a sus empleados.

Para potenciar la ayuda a los sectores productivos, pero sobre todo a aquellas personas que perdieron sus empleos por la crisis, se implementaron los programas denominados "Fondo de Asistencia Solidaria para Empleados (FASE)" y "Quédate en Casa", que cubrirían a 5.2 millones de dominicanos. El programa FASE es un apoyo a las empresas para que puedan mantener a sus empleados, pagando hasta $\operatorname{RD} \$ 8,500$ del salario; y a través de "Quédate en Casa" el gobierno apoya a las familias más pobres (811,000 familias), aumentando las transferencias del programa "Solidaridad" de RD\$ 1,500 a RD\$ 5,000 pesos mensuales. Además, se agregaron otras 690,000 familias categorizadas como pobres o vulnerables por el Sistema Único de Beneficiario (SIUBEN) que también recibieron el apoyo económico temporal "Quédate en Casa”. Para los hogares donde el jefe de hogar es particularmente vulnerable al coronavirus, se adicionó una transferencia de $\mathrm{RD} \$ 2,000$ pesos (un total de $\mathrm{RD} \$$ 7,000 pesos para más de 350 mil hogares). Con estas medidas se busca que un mayor número de familias no caigan bajo el umbral de la pobreza.

Por otro lado, el Banco Central redujo la tasa de política monetaria, del 4.5\% al 3.5\% anual, la tasa de interés de la línea de expansión de liquidez permanente, del 6.0\% al 4.5\% anual, y la tasa de interés en depósitos a corto plazo que devengan intereses en el Banco Central, de 3.0\% a 2.5\% anual. También implementó medidas de provisión de liquidez para el sistema financiero, tanto en moneda nacional como extranjera por RD\$ 80.2 mil millones. Adicionalmente, se establecieron medidas especiales de tratamiento regulatorio para el sistema financiero, las cuales permitirían el reajuste del calendario de pagos de los deudores bancarios si fuera necesario, sin costos regulatorios adicionales derivados de esta acción. Para fines del mes de agosto el Banco Central volvió a reducir la tasa de política monetaria en 50 puntos básicos. 
En lo que respecta a las micros, pequeñas y medianas empresas (MIPYMES), con el objetivo de preservar empleos y la continuidad de sus funciones, se adoptaron un conjunto de políticas orientadas a mejorar sus flujos de caja y las condiciones financieras de las mismas. Para lograr este propósito, se habilitó una ventanilla de liquidez de corto plazo por hasta RD \$ 15 mil millones para ser canalizados al financiamiento de las MIPYMES y otros microcréditos, a través del Banco de Reservas y del resto las entidades de intermediación financiera que estén interesadas en acceder a esta facilidad. Las entidades financieras accederán a estos recursos por un plazo de un ańo, a una tasa de interés de $3.50 \%$, utilizando como garantía los títulos de deuda pública y los del Banco Central. El objetivo de esta medida es que las entidades financieras canalicen estos fondos para préstamos a las MIPYMES y a las entidades financieras y programas especializados en el financiamiento a este segmento a una tasa de interés no mayor de 8.0\% anual. Adicionalmente, la Junta Monetaria autorizó la liberación de unos $\mathrm{RD} \$ 5.6$ mil millones del encaje legal (equivalente a $0.5 \%$ ) para el refinanciamiento y consolidación de préstamos a MIPYMES y microcréditos, así como para la canalización de financiamiento de mediano plazo para las empresas de este sector a través de todas las entidades financieras, a una tasa de interés no mayor a $8.0 \%$ anual.

Para los hogares, el sistema financiero ha procurado establecer facilidades que sirvan de soporte para las familias que podrían ver sus ingresos mermados ante la situación actual. Específicamente, durante los meses de abril, mayo y junio de 2020, los bancos comerciales eliminaron el pago mínimo mensual sobre el balance de la deuda de las tarjetas de crédito.

\section{Literatura relacionada}

El Covid-19 ha provocado un shock macroeconómico inusual, aunque la mayoría de los economistas están de acuerdo en que combina aspectos de shocks de oferta y de demanda (Baldwin y Weder di Mauro, 2020) no hay consenso de dónde se produce primero. Para Weder di Mauro (2020) primero ocurre un shock de oferta con las interrupciones de la cadena de suministro, luego se produce un shock a la demanda, cuyas primeras víctimas son las industrias de transporte y hotelería. Los puertos 
y terminales aéreas se enfrentan al mismo tiempo a una fuerte caída en los ingresos, mayores costos por la congestión debido a la acumulación de contenedores vacíos y solicitudes de los clientes para renunciar a los cargos de almacenamiento debido a "causas de fuerza mayor". Mientras que para Baldwin y Tomiura (2020) es indiferente cuál se produce primero. Para estos autores tanto el shock de oferta como el de demanda afectarán negativamente el comercio internacional de bienes y servicios. En la medida en que el COVID-19 sea un shock de oferta, las exportaciones caerán, y caerán más en las naciones más afectadas, y en la medida en que sea un shock de demanda, las importaciones caerán, y caerán principalmente en los socios comerciales de las naciones más afectadas.

Por su parte, Fornaro y Wolf(2020) estudian el impacto del COVID-19 en la economía global utilizando un modelo basado en la nueva economía keynesiana (New Keynesian) donde suponen que la pandemia tiene efectos persistentes en la capacidad productiva en el futuro, al reducir el crecimiento de la productividad agregada (shock de oferta). En consecuencia, la pérdida esperada en ingresos futuros reduce la demanda agregada. Los autores muestran que puede producirse un ciclo de retroalimentación entre la oferta y la demanda agregada si el crecimiento de la productividad depende del nivel de actividad económica, y concluyen que podrían ser necesarias intervenciones políticas drásticas, tanto monetarias como fiscales, para evitar que este shock negativo de la oferta afecte gravemente el empleo y la productividad. Asimismo, Guerrieri, et al. (2020) argumentan que el shock económico asociado con la epidemia de COVID-19 se inicia por el lado de la oferta (cierres, despidos y quiebras de empresas) y provoca cambios, aún mayores, en la demanda agregada. Los autores muestran que en economías con mercados incompletos y consumidores con liquidez limitada es más probable que se cumplan las condiciones para los choques de oferta keynesianos. Las quiebras de empresas y la destrucción del trabajo pueden amplificar el efecto inicial, agravando la recesión. Además, sostienen que el estímulo fiscal estándar puede ser menos efectivo de lo habitual porque el hecho de que algunos sectores estén cerrados disminuye la retroalimentación del multiplicador keynesiano. La política monetaria, siempre que no se vea obstaculizada, puede tener efectos magnificados, evitando las quiebras. Los autores plantean que la respuesta económica debería estar puramente enmarcada en términos 
de seguridad social. De igual forma, Baqaee y Farhi (2020) sostienen que el impacto del COVID-19 en la economía no puede categorizarse fácilmente como un shock de oferta o de demanda agregada. Por el contrario, lo consideran como una combinación desordenada de oferta y demanda. Los autores utilizan un modelo keynesiano desagregado con múltiples sectores para comprender cómo la crisis de COVID-19 afecta la producción, el desempleo y la inflación en los Estados Unidos, y calibran su modelo con datos desglosados usando la matriz insumo-producto e ilustran la intuición utilizando una representación de $O A-D A$ no lineal. Ellos encuentran que las perturbaciones negativas de la oferta producen estanflación y que las perturbaciones negativas de la demanda son inflacionarias. Concluyen señalando que los shocks sectoriales de oferta y demanda explican aproximadamente la mitad de la reducción en el PIB real, el 3\% de inflación y hasta $10 \%$ de desempleo en el mes de abril de 2020 .

En cambio, del Rio-Chanona et al. (2020) proporcionan predicciones cuantitativas de los shocks de oferta y demanda asociados con la pandemia de COVID-19 en la economía de los Estados Unidos. Para analizar el shock de oferta, los autores desarrollan un índice de teletrabajo con la finalidad de estimar el grado en que los trabajadores pueden realizar actividades asociadas con su ocupación desde el hogar e identifican cuáles industrias se clasifican como esenciales y no esenciales. En cuanto a la demanda, los cambios se estiman por la respuesta inmediata de la gente a la pandemia, dados por el aumento en la demanda de atención médica y/o las reducciones en la demanda de aquellos bienes y servicios que puedan poner a las personas en riesgo de infección. En comparación con el período anterior al COVID-19, estas perturbaciones amenazarían alrededor del 22\% del PIB de la economía estadounidense, pondrían en peligro el $24 \%$ de los empleos y reducirían el ingreso salarial total en un $17 \%$. De forma similar, Brinca, Duarte y Faria e Castro (2020) estudian el impacto del COVID-19 sobre las tasas de crecimiento de horas trabajadas y salarios reales para los principales sectores de la economía de los Estados Unidos. Los autores estiman un vector autorregresivo estructural bayesiano (SVAR) usando estadísticas mensuales de horas trabajadas y salarios reales para los Estados Unidos en el período comprendido entre marzo 2006 y abril 2020. Sus resultados sugieren que dos tercios de la caída en la tasa de crecimiento de las horas 
trabajadas en abril de 2020 son atribuibles a un shock de oferta laboral. Los autores sugieren que la mayoría de los sectores estuvieron sujetos a choques de oferta y demanda laboral negativos en marzo y abril, pero existe una heterogeneidad sustancial en el tamaño de los choques entre sectores. Además, muestran que los shocks de oferta están correlacionados con medidas sectoriales de teletrabajo.

Asimismo, Bekaert, Engstrom y Ermolov (2020) estudian las fluctuaciones de la producción y los precios en la economía de los Estados Unidos, durante la pandemia del COVID-19. Los autores explotan las características no gaussianas de las revisiones de pronósticos macroeconómicos e imponen supuestos teóricos mínimos. El bloqueo masivo de la economía representa un gran shock negativo de la demanda, sin embargo, un aumento concomitante en los beneficios por desempleo ha aumentado los ingresos de algunos hogares de ingresos bajos y medianos al menos temporalmente, lo que podría ayudar de manera útil a la demanda agregada. En sus resultados atribuyen dos tercios de la disminución del PIB del primer trimestre de 2020 a un shock negativo de la demanda agregada. Mientras que dos tercios de la disminución del PIB en el segundo trimestre se debió a una reducción en la oferta agregada. El análisis estadístico sugiere una recuperación lenta debido a los efectos persistentes del shock de oferta.

\section{Aspectos metodológicos}

Para entender el impacto de la crisis sanitaria en una economía pequeña como la dominicana, utilizamos un modelo de oferta y demanda agregada siguiendo el esquema desarrollado por Galí (2008) y Bajo y Díaz (2011 y 2013) y suponemos que la economía tiene dos sectores: un sector real (mercado de bienes) y un sector monetario (mercado financiero). La condición de equilibrio en el mercado de bienes (sector real) de la economía está dada por:

$$
Y=P I B=C+I+G+X N
$$

donde el producto interno bruto $(Y)$ es igual a la suma del consumo de las familias $(C)$, la inversión de las empresas $(I)$, el gasto de gobierno 
o política fiscal $(G)$ y las exportaciones netas o balanza comercial $(X N)$. La función de consumo estará dada por:

$$
C=C_{A}+c[(1-t) Y+\operatorname{Tr}]
$$

donde $C_{A}$ es el consumo correspondiente al nivel mínimo de subsistencia, con independencia del nivel de ingreso, es decir, el consumo autónomo. En esta parte hacemos el supuesto adicional de que $C_{A}$ recoge el efecto de las expectativas sobre el ingreso futuro (el grado de confianza de los consumidores) ${ }^{1}$ que podemos considerar exógenas a corto plazo. La variable $c$ es la propensión marginal al consumo. Además, las familias pagan impuestos proporcionales a su nivel de ingresos $(t Y)$ y reciben transferencias del gobierno $(T r)$.

Con respecto a función de inversión, hacemos el supuesto de que tanto la depreciación como la inversión planeada en existencias son exógenas, por tanto, la demanda de inversión planeada será una función decreciente del tipo de interés real y, en su forma más simple, podemos escribirla como una función lineal:

$$
I=I_{A}-h r
$$

donde $I_{A}$ es la inversión autónoma que incluye la inversión planeada en existencias, la depreciación, así como otros determinantes de la inversión influidos por las expectativas de los empresarios sobre sus beneficios futuros y, en general, sobre la marcha de la economía; $r$ es la tasa de interés real que se obtiene de restar al tipo de interés nominal (i), que representa el costo de oportunidad de invertir en bienes de capital en lugar de adquirir bonos, la tasa de inflación esperada, $\left(r \equiv i-\pi^{e}\right)$, que suponemos dada a corto plazo y que indica la pérdida de valor, en términos porcentuales, de una cantidad dada de bonos; y $h$ representa la sensibilidad de la inversión a la tasa de interés.

En cuando a la actividad del sector gobierno $(G)$, suponemos que éste realiza gasto público en forma de compras de bienes a las empresas,

\footnotetext{
${ }^{1}$ El consumo de las familias depende del ingreso actual y también del ingreso futuro esperado; que hemos incluido en el consumo autónomo, y de ahí que adquiera importancia la forma en el que los individuos o las familias formen sus expectativas.
} 
concede transferencias $(T r)$ a las familias y recaudas impuestos $(t)$ para financiar el gasto público y las transferencias. La intervención del gobierno en la economía mediante la recaudación de impuestos, y la realización del gasto público y las transferencias, constituye la política fiscal. Suponemos, además, que las decisiones del gobierno son esencialmente políticas por lo que no analizaremos el proceso de toma de decisiones del gobierno. El objetivo de la política económica de las autoridades fiscales será el de contrarrestar las fluctuaciones del nivel de actividad por el impacto del coronavirus, intentando acercar el nivel de ingreso efectivo de la economía a su nivel potencial.

En la parte externa, la función para el saldo de la balanza comercial será:

$$
X N=X N_{A}+x Y^{*}-m Y-v Q
$$

donde $X N_{A}$ representa el componente autónomo de las exportaciones netas; y $x, m$ y $v$ indican la sensibilidad de las exportaciones al producto interno bruto del resto del mundo $\left(Y^{*}\right)$, de las importaciones al PIB nacional $(Y)$, y del conjunto de la balanza comercial al tipo de cambio real $(Q)$, respectivamente. El tipo de cambio real es el precio de los bienes nacionales en términos de los bienes del resto del mundo ${ }^{2}$, y le suponemos una función como la siguiente:

$$
Q=Q_{A}-q\left(r-r^{*}\right)
$$

donde $Q_{A}$ representa el componente autónomo del tipo de cambio real; y $q$ indica la sensibilidad del tipo de cambio real al diferencial de tipos de interés reales entre la economía doméstica $(r)$ y la del resto del mundo $\left(r^{*}\right)$.

Sustituyendo las funciones de consumo, inversión y exportaciones netas en la condición de equilibrio, ecuación (1), y luego agrupando términos y despejando $Y$ obtenemos:

$$
Y=\underset{1-c(1-t)+m}{1}\left[\left(C_{A}+c \operatorname{Tr}+I_{A}+G+X N_{A}+x Y^{*}-v Q_{A}-v q r^{*}\right)-r(h+v q)\right]
$$

\footnotetext{
${ }^{2}$ Para un análisis del tipo de cambio real en la República Dominicana ver a Cruz-Rodríguez (2016).
} 
La ecuación (6) es la función inversión-ahorro o IS (siglas en inglés de investment-saving) que representa el conjunto de pares de puntos del nivel de ingreso-tasa de interés real que mantienen en equilibrio el mercado de bienes. Adicionalmente, vamos a suponer que los parámetros de las funciones de comportamiento del sector privado (economías domésticas y empresas) son estables. De acuerdo a esto, tanto la propensión marginal al consumo $(c)$, como la sensibilidad de la inversión respecto al tipo de interés real $(b)$, permanecerán invariables; por tanto, alteraciones de la posición de la función $I S$ vendrán dadas por variaciones de los componentes autónomos del consumo $\left(C_{A}\right)$, la inversión $\left(I_{A}\right)$, de las exportaciones neta $\left(X N_{A}\right)$ y del tipo de cambio real $\left(Q_{A}\right)$, así como de variaciones en el nivel de ingreso del resto del mundo, de las sensibilidades de las exportaciones a $Y^{*}$, de las importaciones al PIB nacional, de la balanza comercial al tipo de cambio real, la del tipo de cambio real a las tasas de interés real doméstica y la del resto del mundo. Finalmente, se producirán variaciones cuando existan movimientos en los instrumentos de política fiscal $(G, \operatorname{Tr} \mathrm{y} t)$.

En cuanto a la condición de equilibrio del mercado monetario suponemos que la política monetaria sigue una regla de Taylor de la siguiente forma:

$$
r=r_{A}+a\left(\pi-\pi^{o}\right)+b Y
$$

donde $r$ es la tasa de interés real, $r_{A}$ es un componente autónomo que representa el valor de referencia para el tipo de interés real de largo plazo, $r_{A}=\bar{r}$, y $a$ y $b$ son el coeficiente de variación de la inflación con respecto a la inflación objetivo $\left(\pi^{o}\right)$ y el del nivel de producción, respectivamente ${ }^{3}$. El Banco Central anuncia en cada período un objetivo para la tasa de inflación $\left(\pi^{o}\right)$, y corrige la tasa de interés en función de las desviaciones de la tasa de inflación efectiva con respecto a su objetivo en una proporción a. El Banco Central aumentará la tasa de interés cuando la tasa de inflación sea mayor a la inflación objetivo. Asimismo, el Banco Central intentará influir sobre el nivel de actividad, reduciendo la tasa de interés en una proporción $b$, cuando disminuya el nivel de actividad. El objetivo de las

\footnotetext{
${ }^{3}$ El banco central fija inicialmente la tasa de interés real $(r)$ con un valor igual al de la tasa natural de interés $(\bar{r})$.
} 
acciones de política monetaria a corto plazo debería ser la estabilización de la tasa de inflación en torno a un objetivo (inflation targeting), en combinación con la estabilización del nivel de actividad en torno a su valor potencial. Suponemos que los parámetros de la función de comportamiento del banco central ( $a$ y $b$ ) son estables; y que el valor de referencia para la tasa de interés real $r_{A}$ está dada a mediano plazo. Por ende, las perturbaciones monetarias se producirán por actuaciones de política monetaria, a través de variaciones de la tasa de inflación objetivo $\left(\pi^{\circ}\right)$. Aquí la política monetaria está planteada acorde a los modelos de la nueva economía keynesiana (Lizarazu, 2014), en donde se sustituye la LM tradicional por la función de regla monetaria siguiendo a Romer (2000). Por tanto, el equilibrio de corto plazo estará dado por el modelo IS-RM.

Sustituyendo en la función $I S$ la tasa de interés real dada por la función $R M$ obtenemos la función de demanda agregada $(D A)$ :

$$
\begin{array}{r}
Y=\frac{1}{1-c(1-t)+m+b(h+v q)}\left[C_{A}+c T r+I_{A}+G-r_{A}(h-v q)-a \pi(h+v q)+\right. \\
\left.a \pi^{o}(h+v q)+X N_{A}+x Y^{*}-v Q_{A}-v q r^{*}\right]
\end{array}
$$

La ecuación (8) muestra una relación decreciente entre el nivel del producto y la tasa de inflación. Al igual que en el modelo $I S-R M$ seguimos suponiendo que son estables los parámetros de las relaciones de comportamiento, tanto del sector privado (economías domésticas y empresas) en las funciones de consumo e inversión, como del banco central en la regla de política monetaria; supondremos también como dado el valor de referencia para la tasa de interés real en el largo plazo. Por tanto, las perturbaciones de la demanda interna de bienes o demanda agregada $(D A)$ vendrán dada por variaciones en $C_{A}, I_{A}, X N_{A}, Q_{A}, G, T r, t, Y^{*}, r^{*}$ y $\pi^{o}$.

Con respecto a la oferta agregada, la misma se modela como una relación dinámica a partir de una curva de Phillips como la estimada por Cruz-Rodríguez (2008a) para la economía dominicana. La ecuación de $O A$ la expresamos de la siguiente forma:

$$
\pi=\pi_{-1}-\dot{Q}_{-1}+(Y-\bar{Y})+Z_{w}+u
$$

donde $\pi$ es la inflación doméstica, $\pi_{-1}$ es la tasa de inflación esperada aproximada por la tasa de inflación del período anterior, $\dot{Q}_{-1}$ es la tasa de 
variación del tipo de cambio real en el período anterior; $(Y-\bar{Y})$ es la diferencia entre el PIB realizado y el PIB potencial; $Z_{w}$ recoge la variación de los factores exógenos (distintos de la productividad del trabajo) que afecta a la determinación de precios y salarios (poder de mercado de las empresas y de los trabajadores, tasas de las cotizaciones a la seguridad social a cargo de los empresarios y a cargo de los trabajadores, precio de las materias primas de importación, tasa impositiva sobre el salario nominal y tasa de impuesto indirecto), y $u$ es una perturbación exógena.

Una vez hemos asentado las bases del modelo de $O A-D A$, ecuaciones (8) y (9), tenemos los instrumentos básicos que necesitamos para analizar la fluctuación de la actividad económica producida por la crisis del COVID-19. Para ello, hacemos el supuesto adicional de que los precios se ajustan gradualmente en respuesta a una perturbación y que en el mediano plazo el nivel de producción potencial se explica a partir de la aparición de perturbaciones originadas en la oferta agregada.

\section{Análisis del impacto del COVID-19 en oferta y demanda agregada}

Los efectos de COVID-19 para una economía pequeńa y abierta, como la dominicana, se muestran en la Figura 1, donde se representan las funciones $O A$ y $D A$ (mediano plazo) y las funciones $I S$ y $R M$ (corto plazo) en las partes superior e inferior izquierda de la figura, respectivamente, y el tipo de cambio real en la parte inferior derecha. Partiendo de una situación inicial de equilibrio a mediano plazo (gráfico superior derecho) dada por el punto $E_{0}$, con unos valores iniciales del nivel de producción (igual al potencial) y la tasa de inflación interna $\left(\pi_{0}\right)$, y de corto plazo con el PIB potencial $\left(\bar{Y}_{0}\right)$, la tasa de interés real $\left(r_{0}\right)$ y el tipo de cambio real $\left(Q_{0}\right)$; la paralización del turismo y la actividad empresarial, como medida para frenar la propagación del virus, afectó inicialmente a la oferta agregada de la economía provocando una disminución de la producción. Este shock de oferta conlleva a un desplazamiento de la curva de $O A$ hacia la izquierda. Manteniéndose todo lo demás constante, en el mediano plazo el nivel general de precios de la economía subirá produciendo una mayor inflación $\left(\pi_{0}^{\prime}\right)$ y una menor producción, que pasarás desde $\bar{Y}_{0}$ a $Y_{0}^{\prime}$. En el punto $E_{0}^{\prime}$ tenemos que la producción efectiva estará por debajo de la potencial. 
Los consumidores perciben que la reducción de la producción provocará escasez y, por ende, un aumento de los precios y, dada la crisis sanitaria, se lanzan a los supermercados a abastecerse de productos alimenticios y materiales para la limpieza e higiene personal. Concomitantemente, se produce un incremento de la demanda por liquidez, tanto de las familias como de las empresas para hacer frente a lo desconocido, esto último implica que las familias guardan o atesoran una parte importante de la liquidez (demanda de dinero por precaución). Además, las familias perciben que los efectos de la reducción de la producción presionan al alza el desempleo que, unido al aumento de la incertidumbre, reducirán el consumo privado (reducción de la variable $C_{A}$ ) porque se deterioran las expectativas sobre el ingreso futuro y/o el grado de confianza de la economía. De igual forma, se reduce la inversión $\left(I_{A}\right)$ por un deterioro en las expectativas de los empresarios sobre sus beneficios futuros $y$, en general, sobre la marcha de la economía. Los agentes aumentan su atesoramiento "precautorio" en un contexto de mayor incertidumbre, es decir, dejan de gastar por lo que pueda venir (incrementando el ahorro). Tanto la incertidumbre de los consumidores como la de los inversionistas están relacionada con factores psicológicos productos de la pandemia, lo que Keynes denominó espíritus animales.

Las disminuciones del consumo autónomo y de la inversión autónoma producirán una contracción de la demanda agregada mayor a la producida en la oferta agrega, generándose un efecto de empobrecimiento de las familias. Para evitar el incremento del desempleo, las autoridades buscan neutralizar parcial o totalmente el efecto desfavorable del shock de oferta sobre la producción tratando de incrementar el nivel de demanda agregada por medio de políticas fiscales y monetarias expansivas. Un supuesto importante para el análisis es que la economía opera con un déficit fiscal, por tanto, tiene restricciones presupuestarias importantes para incrementar los niveles de gasto público.

Con respecto a la política monetaria, las medidas adoptadas buscaron suavizar las condiciones monetarias con el objetivo de ayudar a las empresas mediante líneas de crédito flexible, y con ello, impulsar la inflación que se encuentra por debajo del objetivo de $\pm 4 \%$ anual. En el corto plazo, el Banco Central actuó reduciendo la tasa de interés nominal y, en consecuencia, la tasa de interés real en respuesta a la menor tasa de inflación 
y para fomentar un incremento de la inversión, pero mantuvo su inflación objetivo para el mediano plazo como se manifiesta en el marco macroeconómico 2020-2024 (Ministerio de Economía, planificación y Desarrollo, 2020). Sin embargo, el cierre de las actividades productivas no permitió que los empresarios aprovechen la reducción de las tasas de interés para incrementar la inversión, persistiendo la incertidumbre.

Por el lado de la política fiscal, se incrementaron las transferencias a los hogares con miras a suavizar el consumo y evitar que un alto número de la población pase el umbral de pobreza (Gómez, et al. 2020). Las transferencias podrían estar haciendo la función de un subsidio de desempleo y aunque hayamos supuesto que las mismas son variables exógenas en nuestro modelo, pueden servir como ejemplo de estabilizador automático. Así, ante un descenso del nivel de actividad que llevase aparejado un aumento de la tasa de desempleo, aumentarían las transferencias recibidas por los individuos; de esta forma, dependiendo del grado de cobertura proporcionado, se podría paliar una parte de los efectos negativos del descenso del nivel de actividad.

Sin embargo, el confinamiento de las familias provocó un incremento en el consumo de la energía eléctrica, principalmente en las de clase media que representa el 35\% de la población. Las empresas distribuidoras de electricidad (Edenorte, Edesur y Edeeste) manejan una escala de precio por kilowatts $(\mathrm{kw})$ consumido en las tarifas, que son fijadas para las residencias y los comercios en baja tensión y que demandan menos de $10 \mathrm{kw}$ de potencia. Su costo es determinado mediante resoluciones publicadas por la Superintendencia de Electricidad (SIE), por lo cual dependiendo de la cantidad de kilowatts serán el valor de la tarifa. Este sistema asume que el usuario cuyo consumo mensual esté ubicado en renglones de bajo consumo, es porque su nivel salarial y equipamiento en su vivienda se ajusta al comportamiento de una persona de bajos recursos, y por ello recibe el subsidio que ofrece el Estado dominicano. Si el hogar consume 150 kilowatts al mes, el precio que pagará por cada kilowatt por hora es $\mathrm{RD} \$ 4.44$, recibiendo un subsidio equivalente a $\mathrm{RD} \$ 4.27$. No obstante, si el usuario demanda más energía y consumes 400 kilowatts mensual, la tarifa por kilowatts por hora es RD\$10.86 y si consumes más de 700 kilowatts la tarifa se incrementará RD\$11.10 kw/horas. En ese sentido, muchas de las familias de clase media, tanto con jefes de hogares en 
el programa FASE o los que están en teletrabajo o suspendidos, recibieron un incremento de la factura eléctrica debido a que muchos de los miembros del hogar han estado en clases virtuales, tanto a nivel escolar como universitario, además de teletrabajo, se produjo un uso intensivo de juegos electrónicos o un mayor uso del aire acondicionado por el intenso calor, lo que impactó el consumo de kw/hora.

Adicionalmente, el programa FASE sólo estaría apoyando, de manera transitoria, a los trabajadores formales del sector privado, que estuvieran suspendidos con base en las disposiciones vigentes del Código de Trabajo, cuyas empresas se encuentren al día en sus obligaciones de pago con la Tesorería de la Seguridad Social (TSS) para el período febrero de 2020. En consecuencia, un alto número de trabajadores informales no tuvieron apoyo, al igual que aquellos formales cuyos empleadores no estaban al día con la seguridad social. Todo lo anterior, unido la ampliación del confinamiento generó mayor incertidumbre en los consumidores, provocando expectativas negativas sobre la evolución de la economía, lo que implica quiebras y aumento de los despidos, y terminó por generar un efecto contractivo de la demanda agregada, desplazando la curva desde $D A_{0}$ a $D A_{1}$. La reducción de la demanda agregada neutraliza los efectos desfavorables del shock de oferta sobre los precios, dado que en el punto $E_{1}$ tenemos un menor nivel de inflación acorde con el objetivo del Banco Central, sin embargo, el shock en la demanda agregada agrava el efecto del shock de oferta sobre la producción que se aleja mucho más de su nivel potencial. En el corto plazo se produce una reducción de la tasa de interés real desde $r_{0}$ a $r_{1}$, y de la actividad económica producto de las contracciones del $C_{A}$ y la $I_{A}$. En ese sentido, la República Dominicana, que mide su actividad económica de corto plazo a través del índice mensual de actividad económica (IMAE), mostró importantes reducciones desde inicio la suspensión de operaciones en actividades económicas no esenciales alcanzando una caída de $29.8 \%$ en abril con respecto a igual mes de 2019. No obstante, algunos sectores experimentaron shock de demanda positivo, como el comercio minorista que probablemente se benefició cuando la gente dejó de ir a restaurantes y comenzó a comprar más comestibles y cocinar en casa. De igual forma, el sector de venta de computadores probablemente también se benefició, debido los acuerdos de teletrabajo y las clases a distancias. 
En otro orden, con el traspaso desde el punto $E_{0}$ al $E_{1}$ se produce una depreciación del tipo de cambio real, $Q_{0}$ a $Q_{1}$, derivada de la reducción de las exportaciones, el cierre del sector turismo, la reducción, en un principio, de las entradas de remesas y posibles salidas de capitales dada la reducción de tasas de interés que implica una reducción en la brecha de tasas reales entre el país y el exterior. Además, los resultados mostrados en Cruz-Rodríguez (2016) sugieren que una reducción de la inversión tiende a depreciar el tipo de cambio real en la economía dominicana. Para el mes de abril de 2020, la depreciación se ubicó por encima del $8.0 \%$, pero es importante señalar que en los meses preelectorales siempre ocurren presiones en el mercado cambiario del país, producto de las expectativas de los agentes sobre la estabilidad del tipo de cambio (Cruz-Rodríguez, 2008b). No obstante, en esa acelerada ampliación de la brecha negativa del producto, las fuerzas bajistas sobre la inflación más que compensarían los posibles efectos negativos de la depreciación del peso y la contracción de la oferta agregada.

Por otro lado, una mayor depreciación del tipo de cambio real debería mejorar la balanza comercial con un incremento de las exportaciones, pero esto no se produce debido a la débil demanda externa dada la caída del ingreso del resto del mundo $\left(Y^{*}\right)$. Pero es de esperarse que se produzca una fuerte disminución de las importaciones la que estaría compensando con creces la caída de las exportaciones. Aunque no se muestra en el análisis gráfico, las caídas en los ingresos por turismo se traducirían en un deterioro de la cuenta corriente de la balanza de pagos.

Con respecto a la política fiscal, partimos del supuesto de que el gobierno tenía un déficit en $E_{0}$, dado los incrementos del gasto para hacer frente a la pandemia, particularmente en el sector salud, y el incremento por las transferencias a las familias, además, de una disminución de los ingresos, entonces en el punto $E_{1}$ estará presentando un déficit fiscal mayor. Si consideramos que en ese punto tendríamos un PIB doméstico mucho menor, en consecuencia, el déficit como porcentaje del PIB sería alto.

Si nos movemos hacia el mediano plazo, cuando se tenga una apertura completa de la economía el impacto de la contracción de la demanda agregada podría ser aún mayor, dado que una vez desaparezca el programa FASE, las empresas podrían reducir su empleomanía. Asimismo, con el 
confinamiento algunas empresas iniciaron sus ventas de forma virtual, lo que podría motivar a una reducción en el número de tiendas físicas generando, por tanto, mayores niveles de desempleo. Esto, unido al cierre de empresas, el aumento del pesimismo, la paralización de la inversión pública y privada, podría generar una nueva reducción del consumo.

Gráfico 1: Modelo OA-DA en una economía abierta

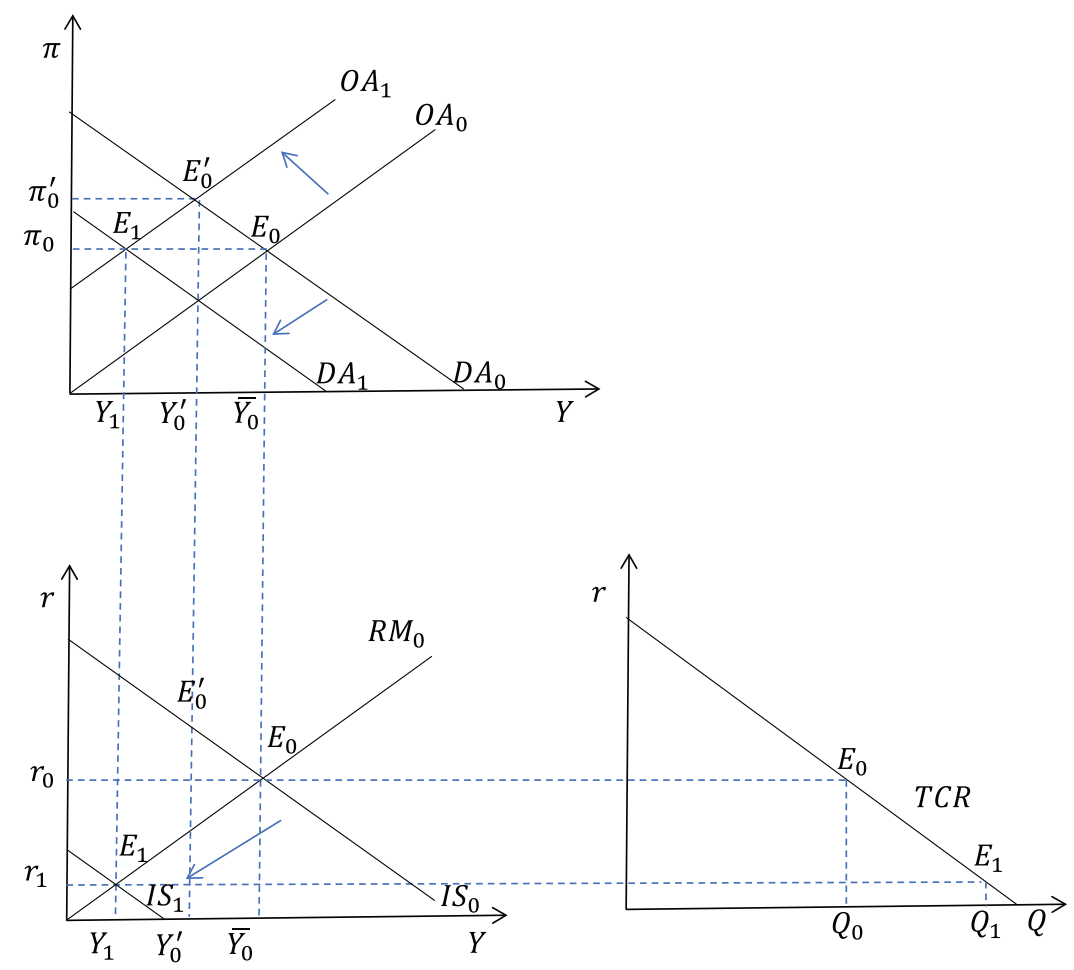

\section{Conclusiones y recomendaciones}

La total paralización del turismo y de la actividad empresarial, como medida para frenar la propagación del COVID-19, afectó inicialmente a la oferta agregada de la economía provocando una disminución de la producción, la cual se agravó con la disminución del consumo y la inversión autónoma, que generó una contracción de la demanda agregada. La medida monetaria de reducción de la tasa de interés real no tiene el 
impacto deseado en la actividad económica debido a las expectativas de los consumidores y los empresarios, es decir, los espíritus animales. En consecuencia, la economía registra niveles de producción por debajo del potencial.

En el corto plazo, los niveles de precios serán inferiores a los de mediano plazo debido a la meta de inflación establecida por el Banco Central. En cuando al déficit fiscal, este crecerá como porcentaje del PIB, por la caída de los ingresos fiscales y el incremento del gasto público y las transferencias a las familias. Por otro lado, el déficit comercial debería reducirse porque la disminución de las importaciones estaría compensando la débil demanda externa de las exportaciones dominicanas. Sin embargo, el déficit en cuenta corriente se ampliará, reflejando fuertes caídas en los ingresos por turismo.

Para volver a la senda de crecimiento anterior al shock negativo provocado por la pandemia es recomendable que las autoridades contribuyan a reducir la incertidumbre, continuando con el apoyo al consumo, a través de medidas de ayudas a las familias en situación precaria y la garantía de al menos cierta parte de los ingresos de los trabajadores. Dado el espacio fiscal limitado, será crucial establecer prioridades y reasignar el gasto para proteger a los más vulnerables. En ese sentido, el gobierno debería realizar capacitación e incurrir en subsidios a la contratación focalizada de los trabajadores más expuestos a sufrir de desempleo por un período más largo, a la vez que pueda facilitar la reasignación de trabajadores de sectores en contracción a sectores con creciente demanda. El apoyo a la exportación neta se considera una medida primordial a corto plazo, como también evitar el colapso de la infraestructura turística. Asimismo, sería recomendable apoyar con liquidez a las empresas que lo necesiten para evitar quiebras que puedan arrastrar al sistema bancario a una nueva crisis financiera y para mantener empleos.

Pero se hace necesario sanear los estados financieros y abordar el sobreendeudamiento particularmente de las MIPYMES. Esto último requerirá de mecanismos que faciliten la reestructuración y disposición de la deuda problemática. Finalmente, habría que revisar si es factible posponer los pagos por impuestos para las micros, pequeńas y medianas empresas. En cuanto a volver a alcanzar los niveles de producción potencial a mediano plazo, será necesario incrementar la demanda agregada a través de un programa de 
inversión pública que ayude a acelerar la recuperación, siempre que exista una margen de maniobra fiscal. El impulso a la inversión una vez que la pandemia esté mejor controlada, a fin de estimular el crecimiento y limitar las secuelas a más largo plazo. Este tipo de inversión pública puede ayudar a que las economías avancen hacia el pleno empleo, al tiempo que se fortalece la productividad del sector privado.

\section{Referencias}

Bajo, O. y Díaz, C. (2011). Teoría y política macroeconómica. Barcelona: Antoni Bosch editor.

Bajo, O. y Díaz, C. (2013). Un nuevo enfoque para el análisis macroeconómico. Revista electrónica sobre la enseñanza de la Economía Pública, 12. Págs. 66-75.

Baldwin, R. y Tomiura, E. (2020). Thinking ahead about the trade impact of COVID-19. En Baldwin y Weder di Mauro (editores). Economics in the time of COVID-19. Págs. 59-71. London: CEPR Press.

Baldwin, R. y Weder di Mauro, B. (2020). Economics in the time of COVID-19. London: CEPR Press.

Baqaee, D. y Farhi, E. (2020). Supply and demand in disaggregated Keynesian economies with an application to the COVID-19 crisis. Working Paper 27152. National Bureau of Economic Research.

Bekaert, G.; Engstrom, E. y Ermolov, A. (2020). Aggregate demand and aggregate supply effects of COVID-19: a real-time analysis. Finance and Economics Discussion Series 2020-049. Washington: Board of Governors of the Federal Reserve System.

Brinca, P.; Duarte, J. B. y Faria e Castro, M. (2020). Measuring sectoral supply and demand shocks during COVID-19. Working Paper 2020-011C. Federal Reserve Bank of St. Louis.

Cruz-Rodríguez, A. (2008a). A Phillips curve for the Dominican Republic. The Empirical Economics Letters. Vol. 7(8). Págs. 845-850.

Cruz-Rodríguez, A. (2008b). Presión y ataques especulativos en el mercado cambiario de la República Dominicana. Texto de Discusión \#15. Ministerio de Economía, Planificación y Desarrollo.

Cruz-Rodríguez, A. (2016). Tipo de cambio real en la República Dominicana: Enfoques alternativos de equilibrio y desalineamiento. Ciencia \& Sociedad. 41(3). Págs. 519-616. 
del Rio-Chanona, R. M.; Mealy, P.; Pichler, A.; Lafond. F. y Farmer, J. D. (2020). Supply and demand shocks in the COVID-19 pandemic: an industry and occupation perspective. Covid Economics, 6. Págs. 65-103.

Fornaro, L. y Wolf, M. (2020). Covid-19 Coronavirus and macroeconomic policy. Working Paper 1168. Barcelona Graduate School of Economics.

Galí, J. (2008). Monetary Policy, Inflation and the Business Cycle: An Introduction to the New Keynesian Framework. Princeton: Princeton University Press.

Gómez, E.; Alcántara, Y.; Majluta, M., Mercado, V. y Cruz-Rodríguez, A. (2020). Impacto del COVID-19 en la pobreza de República Dominicana. Tópico de Coyuntura No. 8. Ministerio de Economía, Planificación y Desarrollo.

Guerrieri, V.; Lorenzoni, G.; Straub, L., y Werning, I. (2020). Macroeconomic implications of COVID-19: can negative supply shocks cause demand shortages? Working Paper 26918. National Bureau of Economic Research.

Lizarazu, E. (2014). La política monetaria en la macroeconomía neokeynesiana. Economía: teoría y práctica. Nueva Época, 40. Págs. 29-59.

Ministerio de Economía, Planificación y Desarrollo (2020). Marco Macroeconómico 2020-2024. Mimeo. http://mepyd.gob.do/ marcomacro.

Romer, D. (2000). Keynesian macroeconomics without the LM curve. Journal of Economic Perspectives, 14(2). Págs. 149-169.

Weder di Mauro, B. (2020). Macroeconomics of the flu. En Baldwin y Weder di Mauro (editores). Economics in the time of COVID-19. Págs. 31-35. London: CEPR Press. 